\title{
Natural history of polypoid lesions in the gall bladder
}

\author{
H Moriguchi, J Tazawa, Y Hayashi, H Takenawa, E Nakayama, F Marumo, C Sato
}

\begin{abstract}
Background-Although polypoid lesions of the gall bladder are frequently observed in asymptomatic subjects, the natural history of these lesions has never been studied using ultrasonography.

Aim-The natural history of polypoid lesions of the gall bladder was investigated using ultrasonography.

Subjects-Among 4343 patients who presented to the outpatient clinic of Tsuchiura Kyodo General Hospital in 1988, 111 subjects were diagnosed as having polypoid lesions of the gall bladder by ultrasonography. Among these patients, two had gall bladder carcinoma. The remaining 109 subjects (58 female; age: median 54, range 25-89) were enrolled in this study.
\end{abstract}

Methods-The subjects were followed up by ultrasonography once or twice a year until 1994.

Results-Four patients received cholecystectomy and two patients died of other causes during the observation period. In one patient, gall bladder carcinoma was found, but its location was different from that of the pre-existing polyp. The size of the lesions did not change in $88.3 \%$ of the other 130 patients during this period, even among those in whom the initial size of the lesion exceeded $10 \mathrm{~mm}$. There was no apparent correlation between the change in the diameter of the polypoid lesions and patients' sex or age.

Conclusion-Most polypoid lesions of the gall bladder detected by ultrasonography are benign.

(Gut 1996; 39: 860-862)

Keywords: gall bladder carcinoma, gall bladder polyp, prognosis, ultrasonography.

Ultrasonography has been widely used in clinical medicine, and its usefulness has been reported in the diagnosis of calculous gall bladder disease. ${ }^{1}$ Mass surveys for abdominal disease have recently been performed using ultrasonography, and polypoid lesions of the gall bladder have been one of the most common findings.

There are several studies that describe the prevalence of gall bladder polyps. ${ }^{2-6}$ One epidemiological study in Japan shows that the prevalence of gall bladder polyps was $6 \cdot 28 \%$ in men and $3.5 \%$ in women, ${ }^{2}$ and another showed $5.3 \%$ in men. ${ }^{3}$ In Denmark, the prevalence was $4.6 \%$ and $4.3 \%$ in men and women, respectively, ${ }^{4}$ and $5.9 \%$ and $5 \cdot 8 \%$ in men and women, respectively, in a 70 year old population. ${ }^{5}$ The prevalence was as low as $1.3 \%$ in the United Kingdom. ${ }^{6}$ However, the only report on the prognosis of polypoid lesions of the gall bladder is an old study using cholecystography. ${ }^{7}$ Therefore, the natural history of patients with polypoid lesions of the gall bladder was studied in this study.

\section{Methods}

Ultrasonographic examinations were carried out on 4343 patients in the outpatient clinic of the Department of Internal Medicine, Tsuchiura Kyodo Hospital from 1 January to 31 December 1988. Among these patients, 111 were diagnosed as having polypoid lesions of the gall bladder. Two of them had gall bladder carcinoma. The remaining 109 subjects (58 females; age: median 54, range 25-89) were enrolled in this study. After an overnight fast, ultrasonographic examination was performed by a radiology licensed :echnician using an Aloka Echo Camera SSD-650CL equipped with a $3.5 \mathrm{MHz}$ transducer (Aloka Co, Tokyo, Japan). Criteria for polypoid lesions of the gall bladder were immobile echoes protruding from the gall bladder wall into the lumen without acoustic shadows. The number of lesions and the diameter of the largest lesions were recorded. The patients were followed up by the same technician once or twice a year until 1994.

Statistical significance was analysed by Mann-Whitney U test or Spearman's rank correlation test, and $\mathrm{p}<0.05$ was considered to be statistically significant.

\section{Results}

Table I shows the size and the number of the polypoid lesions. The polypoid lesions were multiple in $61 \%$ and single in $39 \%$ of the patients. The diameter of the largest lesions was less than $5 \mathrm{~mm}$ in $57 \%$ of the patients, between $6 \mathrm{~mm}$ to $9 \mathrm{~mm}$ in $37 \%$, and more than

TABLE I Size and the number of the polypoid lesions of the gall bladder

\begin{tabular}{lllll}
\hline & \multicolumn{4}{c}{ Initial sizes of the largest polyps in 1988} \\
\cline { 2 - 5 } & $\leqslant 5 \mathrm{~mm}$ & $6-9 \mathrm{~mm}$ & $\geqslant 10 \mathrm{~mm}$ & \multicolumn{1}{c}{ Total } \\
\hline Single & $30(71 \cdot 4)$ & $10(23 \cdot 8)$ & $2(4 \cdot 8)$ & $42(100)$ \\
Multiple & $32(47 \cdot 8)$ & $30(44 \cdot 8)$ & $5(7 \cdot 4)$ & $67(100)$ \\
Total & $62(56 \cdot 9)$ & $40(36 \cdot 7)$ & $7(6 \cdot 4)$ & $109(100)$ \\
\hline
\end{tabular}

Figures in parentheses are percentages. The size of the largest polyps was significantly larger in the multiple group than the single group by Mann-Whitney U test $(p=0.0197)$. 
TABLE II Size of the polypoid lesions of the gall bladder in relation with age

\begin{tabular}{lccccc}
\hline \multicolumn{7}{c}{ Age (y) } & & & \\
\cline { 2 - 6 } & $\leqslant 39$ & $40-49$ & $50-59$ & $60-69$ & $\geqslant 70$ \\
\hline$\leqslant 5 \mathrm{~mm}$ & $7(43 \cdot 8)$ & $12(52 \cdot 2)$ & $18(56 \cdot 3)$ & $17(60 \cdot 7)$ & $8(80 \cdot 0)$ \\
$6-9 \mathrm{~mm}$ & $7(43 \cdot 8)$ & $9(39 \cdot 1)$ & $11(34 \cdot 4)$ & $11(39 \cdot 3)$ & $2(20 \cdot 0)$ \\
$\geqslant 10 \mathrm{~mm}$ & $2(12 \cdot 5)$ & $2(8 \cdot 7)$ & $3(9 \cdot 4)$ & $0(0)$ & $0(0)$ \\
Total & $16(100)$ & $23(100)$ & $32(100)$ & $28(100)$ & $10(100)$ \\
\hline
\end{tabular}

Figures in parentheses are percentages. A statistical correlation was seen between the size of the polypoid lesions of the gall bladder and age by Spearman's rank correlation test $(p=0 \cdot 0490)$.

TABLE III Patients withdrawn during the observation period

\begin{tabular}{llllll}
\hline Patients & Age & Sex & Withdrawn & Cause & Polypoid lesions \\
\hline 1 & 53 & Male & March 1988 & Cholecystectomy & Benign $(10 \times 10 \mathrm{~mm})$ \\
2 & 67 & Female & July 1988 & Cholecystectomy` & Benign $(3 \times 4 \mathrm{~mm})$ \\
3 & 47 & Male & November 1989 & Died (gastric cancer) & Benign $(6 \times 6 \mathrm{~mm})$ \\
4 & 89 & Male & March 1990 & Died (gastric cancer) & Benign $(5 \times 5 \mathrm{~mm})$ \\
5 & 50 & Male & December 1991 & Cholecystectomy & Benign $(7 \times 7 \mathrm{~mm})$ \\
6 & 77 & Female & July 1992 & Cholecystectomy & Adenocarcinoma $(24 \times 15 \mathrm{~mm})$
\end{tabular}

*Cholecystectomy was performed during the operation for early gastric carcinoma.

than $10 \mathrm{~mm}$ in $6 \%$. The size of the polypoid lesions was significantly larger in younger populations (Table II). With the exception of six patients who died or underwent cholecystectomy, all of the patients were followed up for a five year observation period (Table III). Gall bladder carcinoma was found in one patient, who underwent cholecystectomy, but its location was different from that of the preexisting polyp. The size of most of the lesions,

- including even those larger than $10 \mathrm{~mm}$ in diameter, did not change during the observation period (Table IV). There were no apparent correlations between the change in the diameter of the polypoid lesions and patients' sex (Table V) or age (Table VI). None of the patients had gall stones.

TABLE IV Initial sizes of the largest polyps and the change in the diameter of the polypoid lesions of the gall bladder between 1988 and 1993

\begin{tabular}{lcccc}
\hline & \multicolumn{4}{c}{ Initial sizes of the largest polyps in 1988} \\
\cline { 2 - 5 } & $\leqslant 5 \mathrm{~mm}$ & $6-9 \mathrm{~mm}$ & $\geqslant 10 \mathrm{~mm}$ & Total \\
\hline Enlarged $^{\star}$ & $9(15 \cdot 3)$ & $2(5 \cdot 3)$ & $1(16 \cdot 7)$ & $12(11 \cdot 7)$ \\
No change & $48(81 \cdot 4)$ & $34(89 \cdot 5)$ & $5(83 \cdot 3)$ & $87(84 \cdot 5)$ \\
Reduced & $0(0)$ & $2(5 \cdot 3)$ & $0(0)$ & $2(1 \cdot 9)$ \\
Disappeared & $2(3 \cdot 4)$ & $0(0)$ & $0(0)$ & $2(1 \cdot 9)$ \\
Total & $59(100)$ & $38(100)$ & $6(100)$ & $103(100)$ \\
& & & & \\
\hline
\end{tabular}

Figures in parentheses are percentages. A statistical correlation was not seen between the size of the polypoid lesions of the gall was not seen between the size of the polypoid lesions of the gall
bladder and the outcome of the lesions by Spearman's rank bladder and the outcome of the lesions by Spearman's rank
correlation test $(p=0 \cdot 3039)$. ${ }^{\star}$ Changes more than $3 \mathrm{~mm}$ were defined as enlarged or reduced.

TABLE V Sex and the change in the diameter of the polypoid lesions of the gall bladder between 1988 and 1993

\begin{tabular}{lcc}
\hline & \multicolumn{1}{c}{ Male } & Female \\
\hline Enlarged $^{\star}$ & $5(10 \cdot 2)$ & $7(13 \cdot 0)$ \\
No change $_{\text {Reduced }}^{\star}$ & $41(83 \cdot 7)$ & $46(85 \cdot 2)$ \\
Disappeared & $1(2 \cdot 0)$ & $1(1 \cdot 9)$ \\
Total & $2(4 \cdot 1)$ & $0(0)$ \\
& $49(100)$ & $54(100)$ \\
\hline
\end{tabular}

Figures in parentheses are percentages. No sex difference was observed by Mann-Whitney U test $(p=0.3667)$. ${ }^{\star}$ Changes more than $3 \mathrm{~mm}$ were defined as enlarged or reduced.

\section{Discussion}

A polyp-cancer sequence has been especially implicated in cases with gall bladder adenomas, and a follow up observation every six months has been recommended for polypoid lesions smaller than $10 \mathrm{~mm} .^{8}$ However, the only report on the prognosis of polypoid lesions of the gall bladder, was made in an old study using cholecystography. ${ }^{7}$ In this study, we studied the natural history of polypoid lesions of the gall bladder in 109 patients. During the observation period of five years, most of the polyps did not change in size. Although gall bladder carcinoma was found in one patient, its location was different from that of the preexisting polyp. Thus, polypoid lesions of the gall bladder detected by ultrasonography seem to be benign.

Eelkema et al studied 226 patients diagnosed as having polypoid lesions of the gall bladder by cholecystography, and suggested that cholecystographically demonstrated polypoid lesions without stones are benign and remain benign. ${ }^{7}$ Their result is consistent with our findings. In their study, however, 30 of the patients were not available for study, 58 patients were lost during the follow up period, and only 113 patients were analysed after 15 years. Furthermore, cholecystography has much less diagnostic sensitivity than ultrasonography. Therefore, although no malignancies were observed during the follow up period in their study, the actual prognosis of those lesions is not clear.

In a study of 411 patients who underwent cholecystectomy for gall bladder disease, Koga et al found adenocarcinomas in eight patients and benign polyps including cholesterol polyps and adenomatous hyperplasias in 32 patients. ${ }^{9}$ The ratio of malignant disease was high in their study probably because they analysed operated cases who presented to the hospital with symptoms, but this is difficult to confirm because the actual basal diseases were not shown in their report. Many of the patients with gall bladder carcinoma presented symptoms such as upper quadrant, epigastric or colicky pain, or all three, and the size of the lesions was greater than $10 \mathrm{~mm}$ in seven of eight patients. In one patient, the size of the polyp was $5 \mathrm{~mm}$ at presentation but increased rapidly to $10 \mathrm{~mm}$ within five months of follow up. More recently, Chijiwa and Tanaka from the same department reported on 716 cases of cholecystectomy and found 44 cases of polypoid lesions. Among the 44 cases of polypoid lesions, 12 cases were shown to be gall bladder carcinomas. ${ }^{10}$ Again, most of the malignant polypoid lesions had diameters larger than $10 \mathrm{~mm}$. On the other hand, Ukai et al reported a case with cholesterol polyps that changed in size from $9 \times 6 \mathrm{~mm}$ to $12 \times 10 \mathrm{~mm}$ in 10 months, ${ }^{11}$ suggesting that benign polyps also change in size in comparatively short periods of time. In the subjects with multiple lesions, however, it is practically impossible to confirm by ultrasonography whether the largest polyps detected in 1988 were the same as those observed in 1994 . Nevertheless, it is noteworthy that no carcinoma developed in polyps. 
TABLE VI Age and the change in the diameter of the polypoid lesions between 1988 and 1993

\begin{tabular}{lccccc}
\hline & Age $(y)$ & & & \\
\cline { 2 - 6 } & $\leqslant 39$ & $40-49$ & $50-59$ & $60-69$ & $\geqslant 70$ \\
\hline Enlarged $^{\star}$ & $2(13 \cdot 3)$ & $1(4 \cdot 5)$ & $4(13 \cdot 3)$ & $3(11 \cdot 1)$ & $2(22 \cdot 2)$ \\
No change $_{\text {Reduced }}^{\star}$ & $13(86 \cdot 7)$ & $21(95 \cdot 5)$ & $25(83 \cdot 3)$ & $22(81 \cdot 5)$ & $6(66 \cdot 7)$ \\
Disappeared & $0(0)$ & $0(0)$ & $0(0)$ & $1(3 \cdot 7)$ & $1(11 \cdot 1)$ \\
Total & $0(0)$ & $0(0)$ & $1(3 \cdot 3)$ & $1(3 \cdot 7)$ & $0(0)$ \\
& $15(100)$ & $22(100)$ & $30(100)$ & $27(100)$ & $9(100)$ \\
\hline
\end{tabular}

Figures in parentheses are percentages. Statistical correlation was not seen between the outcome of the lesions and the age by Spearman's rank correlation test $(p=0 \cdot 8116)$. ${ }^{\star}$ Changes more than

$3 \mathrm{~mm}$ were defined as enlarged or reduced.

In five patients in this study, the lesions seemed to be benign because they did not change in size during the observation period even when they initially exceeded $10 \mathrm{~mm}$ in diameter. As pathological assessment of the polypoid lesions was not made, however, it remains to be clarified whether polypoid lesions that grew from an initial size that already exceeded $10 \mathrm{~mm}$ were benign or not.

A recent study has shown that a significantly high incidence of gall stone disease was found among subjects with former polyps in the gall bladder, suggesting either that gall bladder polyps may facilitate gall stone formation, or that some of the gall stones may have been misdiagnosed as gall bladder polyps. ${ }^{12}$ In that study, no malignancies were found during the five year follow up period. In our study, however, none of the subjects with polypoid lesions had gall stones five years later.

In conclusions, most polypoid lesions of the gall bladder detected by ultrasonography are benign.

1 Cooperberg PL, Burhenne HJ. Diagnostic technique of choice in calculous gallbladder disease. $N$ Engl $\mathscr{f}$ Med 1980; 302: 1277-9.

2 Segawa K, Arisawa T, Niwa $\mathrm{Y}$, et al. Prevalence of gallbladder polyps among apparently healthy Japanese: ultrasonographic study. Am $\mathcal{F}$ Gastroenterol 1992; 87: 630-3.

3 Shinchi K, Kono S, Honjo S, Imanishi K, Hirohata T. Epidemiology of gall bladder polyps: an ultrasonographic study of male self-defense officials in Japan. Scand $\mathcal{f}$ Gastroenterol 1994; 29: 7-10.

4 Jørgensen T, Jensen KH. Polyps in the gallbladder. A prevalence study. Scand $\mathcal{f}$ Gastroenterol 1990; 25: 281-6.

5 Jorgensen T, Kay L, Schultz-Larsen K. The epidemiology orgensen T, Kay L, Schultz-Larsen K. The epidemiology
of gallstones in a 70-year-old Danish population. Scand of gallstones in a 70-year-old Da

6 Ozmen MM, Patankar RV, Hengirmen S, Terzi MC. Correspondence. Epidemiology of gallbladder polyps. Scand $₹$ Gastroenterol 1994; 29: 480.

7 Eelkema HH, Hodgeson JR, Stauffer MH. Fifteen-year follow-up of polypoid lesions of gall bladder diagnosed by cholecystography. Gastroenterology 1962; 42: 144-7.

8 Aldridge MC, Bismuth $\mathrm{H}$. Gallbladder cancer: the polypcancer sequence. Br $\mathcal{F}$ Surg 1990; 77: 363-4.

9 Koga A, Watanabe K, Fukuyama T, Takiguchi S, Nakayama F. Diagnosis and operative indications for polypoid lesions of the gallbladder. Arch Surg 1988; 123: polyp.

10 Chijiwa K, Tanaka M. Polypoid lesion of the gallbladder: indications of carcinoma and outcome after surgery for indications of carcinoma and outcome after surgery

11 Ukai K, Akita Y, Mizuno S, et al. Cholesterol polyp of the gallbladder showing rapid growth and atypical changes a case report. Hepatogastroenterology 1992; 39: 371-3.

12 Jensen KH, Jørgensen T. Incidence of gallstones in a Danish population. Gastroenterology 1991; 100: 790-4. 